\title{
Erratum to: Individual and Community-Level Determinants of Mental and Physical Health After the Deepwater Horizon Oil Spill: Findings from Two Federal Surveys
}

\author{
Amy Z. Fan, PhD \\ Marta R. Prescott, PhD \\ Guixang Zhao, PhD \\ Carol A. Gotway, PhD \\ Sandro Galea, PhD \\ Erratum to: J Behav Health Serv Res \\ DOI 10.1007/s11414-014-9418-7
}

In the article titled "Individual and Community-Level Determinants of Mental and Physical Health after the Deepwater Horizon Oil Spill: Findings from the Gulf States Population Survey", the authors' degrees were omitted. The correct appearance of the author list is provided above.

Address correspondence to Amy Z. Fan, PhD, Division of Behavioral Surveillance, Public Health Surveillance and Informatics Program Office, Office of Surveillance, Epidemiology and Laboratory Services, Centers for Disease Control and Prevention, Atlanta, GA, USA. Email: afan@cdc.gov.

Guixang Zhao, PhD, Division of Behavioral Surveillance, Public Health Surveillance and Informatics Program Office, Office of Surveillance, Epidemiology and Laboratory Services, Centers for Disease Control and Prevention, Atlanta, GA, USA.

Carol A. Gotway, PhD, Division of Behavioral Surveillance, Public Health Surveillance and Informatics Program Office, Office of Surveillance, Epidemiology and Laboratory Services, Centers for Disease Control and Prevention, Atlanta, GA, USA.

Marta R. Prescott, PhD, Department of Epidemiology, Mailman School of Public Health, Columbia University, New York, NY, USA.

Sandro Galea, PhD, Department of Epidemiology, Mailman School of Public Health, Columbia University, New York, NY, USA.

The online version of the original article can be found at http://dx.doi.org/10.1007/s11414-014-9418-7.

Journal of Behavioral Health Services \& Research, 2014. 123. (c) 2014 National Council for Behavioral Health. DOI 10.1007/s11414-014-9446-3 